\title{
A tecnologia assistiva e os cuidados específicos na concessáo de cadeiras de rodas no Estado do Rio Grande do Norte
}

\author{
Cláudia Regina Cabral Galvão ${ }^{\mathrm{a}}$, Bárbara Iansã de Lima Barroso ${ }^{\mathrm{b}}$, Daniela de Castro Grutt ${ }^{\mathrm{c}}$
}

${ }^{a}$ Mestre em Engenharia de Produção, Universidade Federal do Rio Grande do Norte - UFRN.

Professora Assistente, Departamento de Terapia Ocupacional,

Universidade Federal da Paraíba - UFPB, João Pessoa, PB, Brasil

'Mestre em Engenharia de Produção, Universidade Federal do Amazonas - UFAM, Professora Assistente,

Departamento de Terapia Ocupacional, Universidade Federal da Paraíba - UFPB, João Pessoa, PB, Brasil

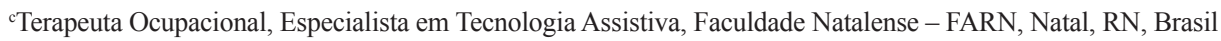

\begin{abstract}
Resumo: O Programa de Concessão de Órteses e Próteses do Estado Rio Grande do Norte foi reestruturado por uma equipe de terapeutas ocupacionais e fisioterapeutas especializados em tecnologia assistiva, que contam com um showroom de equipamentos para dar suporte na realização de prescrições e avaliações de forma individualizada, permitindo a entrega de equipamentos específicos. O programa também possui outros profissionais, como técnicos de oficinas ortopédicas, que fazem o trabalho de ajuste e adaptações das cadeiras de rodas, quando necessário, e assistentes sociais, que seguem todos os processos burocráticos de documentação e de compra das cadeiras de rodas, levando a um fluxo contínuo de entrega de equipamentos ao longo do ano. Esse tipo de organização estrutural pode ser considerado diferenciado do de outros estados. Neste trabalho, um estudo foi promovido para caracterizar a demanda de dispositivos de assistência para locomoção como, por exemplo, cadeiras de rodas, e descrever o processo de licitação e entrega do Programa de Concessão de Órteses e Próteses do Estado do Rio Grande do Norte. O estudo foi conduzido após informações dos últimos três anos do processo de entrega de cadeira de rodas desse programa terem sido analisadas e correlacionadas. Com o fim de promover a inclusão social das pessoas com deficiência, são discutidas a estrutura organizacional, o funcionamento e as facilidades apresentadas.
\end{abstract}

Palavras-chave: Tecnologia Assistiva, Políticas de Saúde, Terapia Ocupacional, Sistema Único de Saúde, Cadeira de Rodas.

\section{Assistive Technology and specific care in the granting of wheelchairs in Rio Grande do Norte state}

\begin{abstract}
The Orthesis and Prosthesis Grant Program from Rio Grande do Norte State was restructured by a team of occupational and physical therapists specialized in Assistive Technology. The sector has a showroom for the equipment, prepares prescriptions, and makes deliveries after individual assessment made by the team. The work is developed in conjunction with orthopedic workshop technicians to adjust and adapt the wheelchairs when necessary. Social workers guide and follow the bureaucratic processes of documentation and purchasing, which allows the handing in of wheelchairs throughout the year. This program is considered distinctive compared to programs from other states. In this work, a study was conducted to characterize the demand for locomotion assistance devices, such as wheelchairs, and describe the delivery and acquisition process of the Orthesis and Prosthesis Grant Program from Rio Grande do Norte State. The study was carried out after analyzing and correlating information on the wheelchair delivery process in the past three years. A discussion on the organizational structure, operation, and acquisition facilities of this program is presented in order to promote the social inclusion of people with special needs.
\end{abstract}

Keywords: Assistive Technology, Health Policy, Occupational Therapy, Unified Health System, Wheelchair. 


\section{Introdução}

Para se chegar à discussão sobre o uso da tecnologia como facilitadora para a vida das pessoas com deficiência, diversas lutas e debates possivelmente aconteceram nas últimas décadas. É possível acompanhar o processo de evolução das concepçóes de deficiência e a forma como a sociedade vem lidando com elas (CRUZ, 2012).

A tecnologia assistiva é definida por Cook e Hussey (2002, p. 05) como

[...] uma ampla gama de equipamentos, serviços, estratégias e práticas concebidas e aplicadas para minorar os problemas encontrados pelos indivíduos com deficiências [...].

É o termo utilizado para identificar um conjunto de recursos e serviços que contribuem para proporcionar ou ampliar habilidades funcionais de pessoas com algum tipo de deficiência.

Este tema, é importante ressaltar, está associado à apresentação de algumas políticas, movimentos sociais e outros marcos que possibilitaram o nível de desenvolvimento da tecnologia assistiva como área de conhecimento no país (CRUZ, 2012).

A Constituição Federal Brasileira, no caput do Art. $5^{\circ}$ ressalta que

[...] todos são iguais perante a lei, sem distinção de qualquer natureza, garantindo-se aos brasileiros e aos estrangeiros residentes no país, a inviolabilidade do direito à vida, à liberdade, à igualdade, à segurança e à propriedade [...] (BRASIL, 1988).

Diante das açóes políticas e sociais desenvolvidas ao longo das últimas três décadas destaca-se a consolidação da Política Nacional de Saúde da Pessoa com Deficiência - Portaria no 1.060/GM, de 5 de junho de 2002; Portaria no 818/GM, de 5 de junho de 2001, que criam mecanismo para organização e implantação das Redes Estaduais de Assistência à Pessoa com Deficiência Física; Portaria $n^{\circ}$ 185/SAS/MS, de 5 de junho de 2001, que inclui a concessão de órteses, próteses e meios auxiliares de locomoção - como marco decisório para um país de todos e para todos.

Atualmente, no Brasil, existem cerca de 45,6 milhôes de brasileiros que possuem algum tipo de deficiência, totalizando $23,9 \%$ da população. A dificuldade de locomoção incide sobre 13,3 milhóes de pessoas, $7 \%$ da população (INSTITUTO..., 2010). Ao lançar o Plano Nacional dos Direitos da Pessoa com Deficiência - Viver sem Limite, por meio do Decreto no 7.612, de 17 de novembro de 2011, o governo federal ressalta o compromisso do país com as prerrogativas da Convenção sobre os Direitos das Pessoas com Deficiência, da Organização das Naçôes Unidas (ONU), ratificada com equivalência de emenda constitucional.

O plano Viver sem Limite possui quatro eixos de atuação, distribuídos nas seguintes linhas: acesso à educação; à saúde; à inclusão social e à acessibilidade. Em suas diretrizes estão a garantia de um sistema educacional inclusivo; de meios de transporte adequados; de acesso a habitação acessível; e a capacitação profissional; além de ampliaçáo do número das pessoas com deficiência no mercado de trabalho; prevenção das causas de deficiência; ampliação e qualificação da rede de atenção à saúde da pessoa com deficiência para serviços de habilitação, reabilitação e desenvolvimento de tecnologia assistiva (BRASIL, 2011).

Entre outras açôes, no eixo da saúde está programada a de ampliação das redes de produção e acesso a Órteses, Próteses e Meios Auxiliares de Locomoção (OPMAL) e no eixo da acessibilidade haverá apoio aos programas de inovação em tecnologia e para aquisição de tecnologias assistivas de forma a incentivar pesquisa e desenvolvimento de novos produtos.

Essa nova abordagem do direcionamento das políticas representa um marco significativo na evolução dos conceitos, em termos filosóficos, políticos e metodológicos, na medida em que propóe uma nova forma de se encarar as pessoas com deficiência e suas limitações para o exercício pleno das atividades decorrentes da sua condição. Por outro lado, influencia um novo entendimento das práticas relacionadas com a reabilitação e a inclusão social dessas pessoas.

$\mathrm{O}$ processo de inclusão vem aos poucos substituindo a prática da integração social partindo do princípio que, para inserir todas as pessoas, a sociedade precisa ser modificada de modo a atender às necessidades dos seus cidadáos. Para tanto, uma sociedade inclusiva náo admite preconceitos, discriminaçóes, barreiras sociais, culturais, arquitetônicas e pessoais e concede a todos o acesso aos serviços públicos, aos bens culturais e aos produtos decorrentes do avanço social, político, econômico e tecnológico da sociedade.

\section{Programa de concessão de órteses, próteses e meios auxiliares de locomoção}

As doutrinas e os princípios do Sistema Único de Saúde (SUS) garantem a todos o direito à saúde. Essa condição se dá, também, mediante a realização 
de açôes de promoção, assistência, prevenção, habilitação e reabilitaçáo, contribuindo para a conquista e preservação do máximo de autonomia e plena capacidade física, mental, social e profissional da pessoa, bem como integral inclusão e participação em todos os aspectos da vida.

Considerando que a concessão das OPMAL é um direito da pessoa com deficiência, ela é essencial para promoção de qualidade de vida dos seus usuários, ampliando as possibilidades de independência do indivíduo nas atividades pessoais, educativas, de lazer e trabalho, entre outras.

A cadeira de rodas faz parte do arsenal de recursos da tecnologia assistiva. Sendo um equipamento que auxilia a locomoção das pessoas com mobilidade reduzida, ela pode ser utilizada por pessoas que apresentam impossibilidade, temporária ou definitiva, de deslocar-se utilizando os membros inferiores, permitindo sua mobilidade durante a realização das atividades de vida diária e prática.

A ideia de suprir essas necessidades possibilitou a criação de diferentes designs de cadeiras de rodas que diferem em forma, material, peso, durabilidade e custo (HUNT et al., 2004).

Moraes (2009) ressalta a importância das superfícies de suporte na cadeira, já que elas podem garantir um cuidado maior com a manutençáo da integridade tecidual, manejo da função digestiva e respiratória, assim como prevençâo de deformidades esqueléticas.

O serviço de concessáo de cadeira de rodas do SUS no Estado do Rio Grande do Norte é coordenado por assistentes sociais e técnicos administrativos que gerenciam todo o processo burocrático. A sede do serviço é no Centro de Reabilitação Infantil (CRI), que também oferece atendimento nas especialidades médicas e de reabilitação a crianças e adolescentes com deficiências.

No Brasil, ainda não há um controle de qualidade normatizado sobre as cadeiras de rodas disponíveis no mercado. Assim, há uma preocupação especial da equipe em garantir a concessão de produtos que ofereçam conforto, resistência, durabilidade e praticidade para o usuário.

Entre as açóes para esse controle, todo o detalhamento dos produtos é descrito nos itens a serem licitados para a aquisição das cadeiras. Foi definido que as empresas que oferecessem serviço de adequação postural e ajustes individuais das cadeiras teriam que ter sede em Natal, RN, para garantia da assistência, qualidade e manutenção dos equipamentos dispensados.
As cadeiras (adulto ou infantil) solicitadas e concedidas pelo setor são fabricadas em alumínio, em sua maior parte, têm pneus infláveis, assento em nylon, apoios de braços e pés escamoteáveis ou removíveis; outras têm assento e encosto anatômicos de fábrica e sistema tilt para inclinação do assento, reclinação do encosto ou ambas funçóes. No setor, grande parte das cadeiras entregues já é recebida com o nome do usuário, pois são feitas pelas fábricas nas medidas solicitadas, para atender às especificidades do cliente.

O serviço conta com a parceria dos técnicos das oficinas ortopédicas para a confecção de adaptaçôes, quando indicadas, para usuários com deformidades mais graves ou com outras necessidades especiais. $\mathrm{O}$ processo de adaptação para conforto e ajuste postural engloba a colocação de cintos, suportes laterais no encosto, rebaixamento de assento, acolchoamento de partes da cadeira, entre outros.

Para o recebimento das cadeiras de rodas, os usuários, quando convocados, comparecem ao setor para conferência das medidas. Na oportunidade, são orientados quanto ao uso adequado da cadeira, sua montagem e desmontagem, cuidados para o manuseio e transporte; quanto ao alinhamento e à adequação postural; e em relação à higienização e manutenção do equipamento.

No Estado do Rio Grande do Norte, todos os municípios são pactuados pela Programação Pactuada Integrada (PPI). O governo do estado complementa a verba para compra e adaptaçáo de todas as cadeiras, além dos outros equipamentos de tecnologia assistiva, através de programação do orçamento anual. Para 2013, a previsão orçamentária para compra de cadeiras, provavelmente, permitirá atender toda a demanda reprimida.

Em outros estados, a realização das licitaçôes é considerada um dos entraves do setor, pois geralmente o processo é lento e muito burocrático. Uma forma encontrada no Rio Grande do Norte para garantir o processo de entrega das cadeiras de rodas durante todo o ano foi descrever no edital de licitação a expressão pedidos de compra realizados trimestralmente. Assim, a cada três meses são recebidos lotes dos equipamentos solicitados (conforme a demanda).

Os profissionais da Terapia Ocupacional e Fisioterapia também acompanham as licitaçōes ocorridas pelo programa repassando o número de cadeiras de rodas pedidas, as especificaçóes dos modelos e dos tamanhos, para que as cadeiras de rodas sejam licitadas atendendo a demanda especificada.

O sistema de concessáo de órtese e prótese e meios auxiliares de locomoção de todo o país, 
a partir da Portaria MS no 971/2012 de 13 de setembro de 2012, teve reconhecido pelo governo federal a necessidade de manutenção e adaptação de aparelhos ortopédicos, auditivos e oftalmológicos. Serão repassados 24,5 milhôes anuais aos estados e municípios que concedem OPMAL, que já constam nos procedimentos da Tabela SUS (BRASIL, 2012a).

A prescrição do equipamento deve ser prioritariamente realizada por um profissional habilitado e a Portaria SAS/MS no 661, de 2 de dezembro de 2010, reconhece o direito de terapeutas ocupacionais e fisioterapeutas prescreverem OPM, ampliando as possibilidades de intervenção desses profissionais no processo terapêutico.

Outra particularidade do serviço é que há uma equipe formada por profissionais da Terapia Ocupacional e da Fisioterapia, especialistas em tecnologia assistiva que trabalham permanentemente no setor. Muitas prescriçóes que dão abertura ao processo vêm apresentando apenas o pedido de "uma cadeira de rodas", sem detalhamento de medidas ou do tipo de cadeira.

Anteriormente às mudanças do setor, esse tipo de pedido impossibilitava que o usuário recebesse uma cadeira que atendesse suas reais necessidades posturais. Muitas pessoas recebiam as cadeiras porque eram gratuitas, só as utilizavam para deslocamentos externos (fora de sua residência), sendo muito limitado o seu desempenho para as demais atividades.

Atualmente, quando as prescriçôes não apresentam as medidas de forma clara e nem especificam o tipo de cadeira de rodas solicitada o usuário é convidado a comparecer ao setor para verificação do tamanho da cadeira e definição do tipo de equipamento que atenderá suas necessidades, só depois é dado seguimento ao processo.

Compete aos profissionais envolvidos no processo o conhecimento de dois aspectos: 1) a variabilidade de equipamentos disponíveis no mercado; e 2) as características do provável usuário. Quanto à variabilidade dos equipamentos, é importante o conhecimento da diversidade dos equipamentos e acessórios dos fabricantes. Em relação às particularidades do usuário, avalia-se seu potencial físico relacionado aos seguintes critérios: condições osteomioarticulares e aspectos neuromotores; condiçôes respiratórias e circulatórias; condiçôes cognitivas (como nível de compreensão e capacidade de aceitação do equipamento); condiçóes funcionais em relação às atividades desempenhadas: de autocuidado, escolares, de trabalho e de lazer; tipo de comunicaçáo; capacidade de realizar transferências e propulsão independente, entre outros (GALVÃO et al., 2008).

\section{Objetivos}

O objetivo deste estudo é descrever o processo de entrega de cadeiras de rodas do Serviço de Concessão de Órteses, Próteses e Meios Auxiliares de Locomoçáo do SUS no Estado do Rio Grande do Norte, caracterizando o perfil da demanda que necessita desse tipo de dispositivo de tecnologia assistiva para auxílio a locomoção.

\section{Metodologia}

De acordo com Vergara (2009), quanto aos fins essa pesquisa é classificada como exploratória, pois seus componentes metodológicos não comportam uma hipótese específica a ser estudada, mas sim a análise das açóes desenvolvidas pelo Serviço de Concessão de Órteses, Próteses e Meios Auxiliares de Locomoção do SUS no Estado do Rio Grande do Norte.

Quanto aos meios de investigação, é classificada como documental, já que houve a realização do levantamento do acervo documental dos processos para a concessáo dos meios auxiliares de locomoção (cadeiras de rodas) entregues no período de janeiro de 2009 a março de 2012, referentes aos anos de 2009 a 2011. Na pesquisa documental, as fontes não receberam tratamento analítico, sendo originais.

A pesquisa também é descritiva, segundo Gil (2002), por caracterizar um serviço, clientela e sua demanda, correlacionando os dados encontrados. Os assuntos e os aspectos a serem discutidos foram fundamentados através de pesquisa bibliográfica.

O levantamento dos arquivos do período estabelecido para a pesquisa identificou os processos de cadeira de rodas entregues pelo número de registro no setor e as informaçóes foram cadastradas em planilha Windows Excel 2008. Os dados coletados se referiram ao nome do indivíduo; município em que residia; idade; nome do profissional responsável pela prescrição; data de abertura do processo e do recebimento da cadeira; tipo de equipamento solicitado e diagnóstico do usuário. Para a discussão dos resultados, os resultados do levantamento foram tratados de forma descritiva.

\section{Resultados e discussão}

A partir do levantamento do acervo documental do setor de concessão, as entregas de cadeira de rodas realizadas até o mês de março de 2012, referentes à 
demanda atendida nos anos de 2009 a 2011, foram investigados 1.884 processos de cadeiras de rodas e de banho entregues.

Quanto às prescriçóes realizadas, os pedidos dos equipamentos foram feitos por profissionais da saúde que detalharam as solicitaçóes para a abertura dos processos. Entre os profissionais que mais prescreveram as cadeiras estão os terapeutas ocupacionais, que encaminharam 734 prescriçôes (39\%); seguidos dos fisioterapeutas, com 707 cadeiras indicadas (38\%); depois, dos médicos, com 381 (20\%). Em conjunto, terapeutas ocupacionais e fisioterapeutas realizaram 62 solicitaçôes (3,3\%).

$\mathrm{O}$ reconhecimento e a regulamentação do terapeuta ocupacional e do fisioterapeuta pelo Sistema Único de Saúde como aptos a prescreverem cadeiras de rodas e outros equipamentos de tecnologia assistiva relacionados a ato não cirúrgico, do tipo órteses, próteses e/ou materiais especiais, atualizou e ampliou a situação documental das prescrições, anteriormente autorizadas apenas por profissional da medicina.

Essa mudança foi de grande relevância no atendimento das necessidades das pessoas com deficiência, pois o terapeuta ocupacional está diretamente ligado ao processo de reabilitação e facilitação da execução das atividades de vida diária e tem grande habilidade para descrever e especificar as medidas dos equipamentos, compreender as necessidades dos usuários, delinear o seu perfil e selecionar as possibilidades de escolha do produto.

A inclusão da tecnologia assistiva nos cursos de graduação dos terapeutas ocupacionais está apenas começando, mas é indiscutível que, em um futuro próximo, essa formação faça parte da maioria das grades curriculares dos cursos de graduação, elevando consequentemente os números da pós-graduação e a qualificação dos profissionais na área (PELOSI, 2005).

Em todo o Estado do Rio Grande do Norte, os tipos de cadeiras entregues aos usuários pelo serviço são detalhadamente descritos e encaminhados ao setor de licitação pela equipe de terapeutas ocupacionais e fisioterapeutas, buscando-se garantir, assim, a qualidade e a resistência dos produtos. $\mathrm{O}$ feedback dos usuários sobre os produtos também é acompanhado pelo setor.

Em relação aos tipos de cadeiras de rodas concedidos, segue-se os modelos de repasse da Tabela SUS, que classifica as cadeiras em tipo padrão, padrão para tetraplégicos, carrinho dobrável para transporte de crianças com deficiência e cadeira para banho com assento sanitário (BRASIL, 2012b).
No período investigado, 982 cadeiras do tipo padrão (52\%) foram entregues. Do total desse modelo, apenas 96 (9,8\%) eram de tamanho infantil; $18(1 \%)$ eram cadeiras para atletas (que permitiam agilidade ao usuário); e apenas 4 (0,2\%) do tamanho obeso. As demais cadeiras desse grupo eram tipo padrão em alumínio, tamanho adulto.

Em relação às adaptaçóes das cadeiras, 110 cadeiras (6\%) foram solicitadas com ajustes em sua prescrição, para adequação postural de seus usuários, que apresentavam algum tipo de deformidade mais grave ou necessidade especial, tendo indicação de colocação de cintos, almofada para apoio dos pés, base rígida, sistema de assento e/ou encosto anatômico, entre outras adaptaçóes.

A cadeira de rodas com recline ou cadeira padrão para tetraplégicos descrita na Tabela do SUS (BRASIL, 2012b) equivale ao modelo que possui o sistema de encosto alto e reclinável para trás. Esse tipo equivaleu a 63 cadeiras de rodas concedidas (3\%).

As cadeiras infantis, do tipo carrinho, que possuíam sistema tilt de inclinação, assento e encosto anatômico, totalizaram 352 (19\%). Essas cadeiras são categorizadas pelo SUS (BRASIL, 2012b) como carrinho dobrável para transporte de criança com deficiência.

As cadeiras de rodas para banho com assento sanitário somaram 487 (26\%), sendo a maioria (372, 20\%) do tipo comum. Cinquenta e cinco outras foram do tipo dobrável (3\%), para facilitar armazenamento em ambientes pequenos; 5 foram do tipo obeso $(0,3 \%) ; 13$ foram cadeiras de banho com sistema reclinável do encosto $(0,7 \%)$ e 42 com apoio de cabeça ou sistema tilt de inclinação (2\%). As cadeiras de banho reclináveis ou com sistema tilt, embora de maior custo, são ideais para pessoas com tetraplegia e que apresentam maior comprometimento motor.

Observa-se uma mudança de conceitos em relaçáo à atividade do banho: anteriormente a indicação do uso de equipamentos, o banho era realizado na bancada da cozinha ou no cháo do banheiro, sem nenhum conforto para a pessoa com deficiência ou para o seu cuidador (DUTRA, 2008).

Em relação à faixa etária dos indivíduos, os resultados encontrados estáo descritos no Quadro 1. Observa-se que havia 774 crianças e adolescentes em idade escolar (41\%) que necessitavam de cadeira de rodas suficientemente confortáveis para permanecerem nelas durante várias horas por dia, garantindo agilidade e segurança para o deslocamento até a escola. 
No total, havia 526 usuários de cadeiras de rodas em idade produtiva (28\%). Assim, observa-se a necessidade de um planejamento do governo para acompanhar a qualificação profissional e a inserção dessas pessoas no mercado de trabalho. A baixa escolaridade e a falta de formaçáo profissional, bem como a precariedade da acessibilidade urbana e do transporte público são discutidas por Rodrigues et al. (2009), como fatores limitantes para a empregabilidade das pessoas com deficiência em idade economicamente ativa, sugerindo a investigação de programas municipais para a criação de uma rede de comunicação, de um cadastro, de programas de qualificação profissional e da inclusão desses indivíduos no mercado de trabalho.

O grupo idosos correspondeu a 584 usuários de cadeira de rodas e de banho (31\%). O crescimento populacional de idosos aponta para o aumento das incapacidades e de agravos à saúde, que deve ser observado no direcionamento das políticas públicas (CRUZ, 2012). A expressividade dos idosos na amostra está apresentada no Quadro 1.

De acordo Unicef/Brasil (BRASIL, 1980), os principais problemas enfrentados pelos países em desenvolvimento, em relaçáo à deficiência, dizem respeito à alta percentagem de famílias pobres; população com alto índice de analfabetismo; e escassos conhecimentos das medidas elementares de saúde, educação e bem-estar. Obstáculos como a falta de recursos financeiros, distâncias geográficas e barreiras sociais privam muitas pessoas da possibilidade de beneficiar-se dos serviços existentes.

Os programas inadequados para a prevenção de agravos, a utilizaçáo dos limitados recursos disponíveis para a prestação de serviços muito especializados, a falta ou insuficiência de uma infraestrutura de serviços conexos de saúde, educação, previdência e preparação profissional, associados à baixa prioridade para as

Quadro 1. Distribuição da faixa etária dos indivíduos da amostra.

\begin{tabular}{|l|c|c|}
\hline \multicolumn{1}{|c|}{ Faixa etária } & $\mathbf{N}$ & $\%$ \\
\hline Menor de 10 anos & 335 & 18 \\
\hline De 11 a 20 anos & 439 & 23 \\
\hline De 21 a 30 anos & 167 & 9 \\
\hline De 31 a 40 anos & 160 & 8 \\
\hline De 41 a 50 anos & 93 & 5 \\
\hline De 51 a 60 anos & 106 & 6 \\
\hline De 61 a 70 anos & 131 & 7 \\
\hline De 71 a 80 anos & 151 & 8 \\
\hline Acima de 80 anos & 302 & 16 \\
\hline Total & 1.884 & 100 \\
\hline
\end{tabular}

atividades relacionadas à reabilitaçáo de pessoas com deficiência são impactantes nas estratégias para o desenvolvimento.

A Figura 1 apresenta o resultado dos diagnósticos mais comuns encontrados na demanda do serviço estudado o resultado dos diagnósticos mais comuns encontrados na demanda do serviço estudado.

Entre os diagnósticos encontrados pela pesquisa estão: paralisia cerebral, com 688 indivíduos (37\%), acidente vascular encefálico, com 218 casos (12\%), paraplegia, com 181 casos (10\%), e amputaçôes, com 100 casos (5\%). Outros diagnósticos e justificativas descritos no encaminhamento para aquisição da cadeira englobam: mobilidade reduzida; doenças neuromusculares; síndromes (Rett, West, Moebius); mielomeningocele; sequela de poliomielite; fratura do fêmur; doenças reumáticas; Alzheimer; traumatismo crânio-encefálico; doença de Parkinson; diabetes; hidrocefalia; obesidade e deficiência mental. $\mathrm{O}$ diagnóstico de 263 cadeiras entregues (14\%) não especificam a prescrição.

Observou-se que 819 cadeiras (43\%) foram concedidas no prazo máximo de 90 dias, sendo 546 (29\%) entregues ao usuário em prazo inferior a 30 dias. Outras 308 cadeiras (16\%) foram entregues entre 6 a 9 meses e 173 (9\%), entregues entre 9 meses a um ano de espera. Apenas 357 cadeiras de rodas (19\%) foram entregues após um ano da abertura do processo.

Açôes do Ministério Público do Rio Grande do Norte anteriormente realizadas através da Promotoria de Justiça de Defesa dos Direitos dos Idosos, das Pessoas com Deficiência e das Minorias Étnicas criaram elementos para essa redução do tempo de espera e do número de pessoas na fila aguardando os equipamentos.

Novas entregas, referentes a solicitaçôes cadastradas todos os anos, são realizadas diariamente. Entretanto, existem diversas cadeiras no estoque do setor, decorrência de dificuldades para localizar os solicitantes quando eles mudam de endereço ou telefone (sem atualizar o cadastro); ou por seu usuário residir em município distante e haver dificuldades de transporte ou para o comparecimento ao setor para conferir as medidas do equipamento e receber orientaçôes quanto ao seu uso (exigência estabelecida para o recebimento da cadeira).

Do total de 167 municípios pactuados em que a Secretaria Estadual de Saúde do Estado do Rio Grande do Norte dinamiza o processo de aquisiçấo dos equipamentos a partir da alocaçáo dos recursos, somente 145 (86\%) deram início ao 


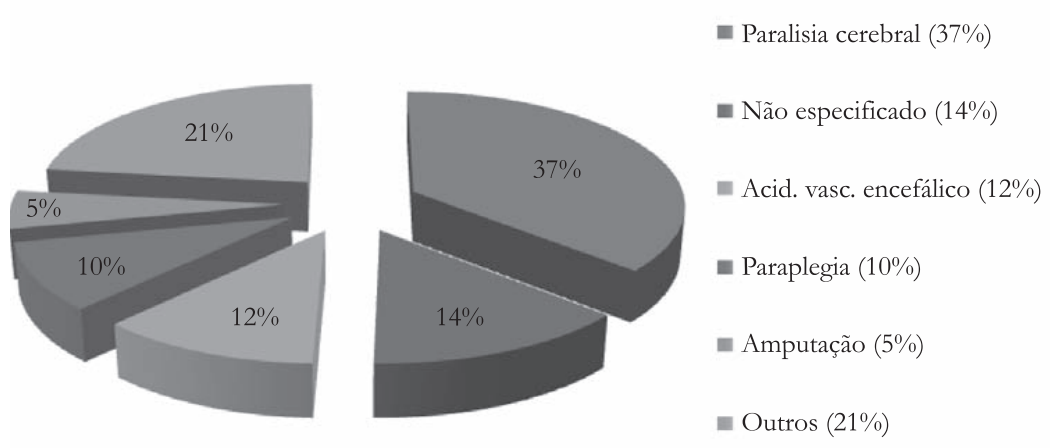

Figura 1. Distribuição dos diagnósticos e percentuais da amostra.

processo de aquisição de cadeiras de rodas (no período investigado).

O maior número de solicitaçôes foi no município de Natal, com 908 processos (48\%), seguido pelo de Parnamirim, com 107 (6\%), depois pelo de Mossoró, com 89 (4,6\%), depois pelo de São José de Mipibu, com 61 solicitaçōes $(3,2 \%)$. Outros quatro municípios receberam entre 30 e 60 cadeiras, apresentando a solicitação média pedido de 41 cadeiras por município, as quais somaram 240 cadeiras, $13 \%$ da amostra. Mais 36 municípios receberam entre 5 e 15 cadeiras, com média de 8,1 cadeiras por município, equivalentes a 244 unidades, $12 \%$ do total; e 100 municípios receberam 5 ou menos cadeiras de rodas (em média, 2,4 cadeiras por município), totalizando 235 das entregas (13\%). A média total de entregas nos 3 anos pesquisados foi de 13 cadeiras de rodas por município.

Sabe-se que a demanda de alguns municípios ultrapassa o repasse do SUS para compra dos equipamentos solicitados, entretanto o governo do estado, através de planejamento anual do orçamento, prevê a complementação do repasse para o setor, a partir da demanda cadastrada pela abertura dos processos. Para o ano de 2013, a previsão é fornecer aproximadamente 2.500 cadeiras de rodas e de banho, com disponibilização de verba para compras na ordem de R \$ 2 milhóes, sem considerar valores para aquisição de outros equipamentos como próteses, outros tipos de órteses e dispositivos de auxílio à locomoção.

\section{Conclusão}

No Estado do Rio Grande do Norte, o Serviço de Concessão de Órteses, Próteses e Meios Auxiliares de Locomoção do SUS dispóe de uma equipe especializada para o atendimento individualizado dos usuários que procuram o setor. $\mathrm{O}$ serviço funciona de forma diferenciada e a partir de ação com o Ministério Público do Estado do Rio Grande do Norte, através da Promotoria da Pessoa com Deficiência, criou elementos para que a Secretaria Estadual de Saúde do estado se reorganizasse e garantisse a concessão de órteses e próteses em prazos minimizados.

Através dos repasses da pactuação instituída pela Programação Pactuada e Integrada, o estado instituiu a compra dos equipamentos e faz uso dinamizado da alocação dos recursos; assim, o setor possui uma abertura mínima de lista de espera para a concessáo dos produtos de tecnologia assistiva (órteses, próteses, meios de locomoção).

Os resultados comprovam a relevância do trabalho com terapeutas especialistas na área de tecnologia assistiva, para que seja esclarecida a necessidade de entrega dos equipamentos apropriados a cada indivíduo, atendendo suas necessidades específicas. É importante fomentar novas discussóes sobre a estruturação do sistema em todo o país, aproveitando a oportunidade de mudanças proposta no Plano Viver sem Limites e outras açóes que viráo no futuro, para que esses serviços proporcionem qualidade de vida às pessoas com deficiência, através do fornecimento de equipamentos que favoreçam e ampliem suas funçóes.

Espera-se em estudos posteriores investigar sobre o uso dos produtos concedidos e que sejam criados elementos para proporcionar a melhoria da qualidade de vida dessa população caracterizada.

\section{Referências}

BRASIL. Constituição, 1988. Constituição da República Federativa do Brasil. Brasília: Imprensa Nacional, 1988. Disponível em: <http://www.planalto.gov.br/ccivil_03/ constituicao/constituicao.htm>. Acesso em: 03 nov. 2012. 
BRASIL. Ministério da Saúde. Viver sem Limite - Plano Nacional dos Direitos da Pessoa com Deficiência. Brasília: Ministério da Saúde, 2011. 43 p. Disponível em: <http:// www.brasil.gov.br/viversemlimite/plano-nacional-dosdireitos-da-pessoa-com-deficiencia>. Acesso em: 02 nov. 2012.

BRASIL. Ministério da Saúde. Portaria no 971, de 13 de setembro de 2012. Adequa o Sistema de Cadastro Nacional de Estabelecimentos de Saúde e inclui Procedimentos de Manutenção e Adaptação de Órteses, Próteses e Materiais Especiais da Tabela de Procedimentos do SUS. Diário Oficial da República Federativa do Brasil, Brasília, DF, 24 set. 2012a. Seção 1. Disponível em: <http://bvsms.saude. gov.br/bvs/saudelegis/sas/2012/prt0971_13_09_2012. html. Acesso em: 02 nov. 2012.

BRASIL. Ministério da Saúde. SIGTAP - Sistema de Gerenciamento da Tabela de Procedimentos, Medicamentos e OPM do SUS. Brasília: Imprensa Nacional, 2012b. Disponível em: <http://sigtap.datasus. gov.br/tabela-unificada/app/sec/procedimento/publicados/ consultar>. Acesso em: 30 out. 2012.

BRASIL. Ministério da Saúde. A deficiência: sua prevenção e reabilitação. Brasília: CORDE, 1980. Relatório da "reabilitação internacional" à junta executiva do UNICEF. COOK, A. M.; HUSSEY, S. M. Assistive Technologies: Principles and Practice. St. Louis: Mosby, 2002.

CRUZ, D. M. C. Papéis ocupacionais e pessoas com deficiências físicas: independência, tecnologia assistiva e poder aquisitivo. 2012. 229 f. Tese (Doutorado)Universidade Federal de São Carlos, São Carlos, 2012. Disponível em: <http://tocoletiva.com.br/wp-content/ uploads/2012/08/TeseDMCC.pdf>. Acesso em: 29 nov. 2012.

DUTRA, F. C. M. Desenvolvimento de protótipo de cadeira de banho para individuos com paralisia cerebral tetraparética espástica. 2008. 132 f. Dissertação (Mestrado em Engenharia de Produção)-Universidade Federal do Rio Grande do Norte, Natal, 2008. Disponível em: <http:// bdtd.bczm.ufrn.br/tedesimplificado/tde_arquivos/6/ TDE-2010-02-07T222656Z-2408/Publico/FabiolaCMD. pdf>. Acesso em: 02 out. 2012.

GALVÂO, C. R. C. et al. Programa de Concessão de Órtese e Prótese no Estado do Rio Grande do Norte: direito e cidadania. Revista Baiana de Saúde Pública, Salvador, v. 32, p. 25-33, jul./dez. 2008. Suplemento 1.

GIL, A. C. Como elaborar projetos de pesquisa. São Paulo: Atlas, 2002.

HUNT, P. C. et al. Demographic and Socioeconomic Factors Associated with Disparity in Wheelchair Customizability Among People with Traumatic Spinal Cord Injury. Archives of Physical Medicine and Rehabilitation, Philadelphia, v. 85, n. 11, p. 1859-1864, Nov 2004. http://dx.doi.org/10.1016/j.apmr.2004.07.347

INSTITUTO BRASILEIRO DE GEOGRAFIA E ESTATÍSTICA - IBGE. Censo Demográfico 2010: Características gerais da população, religião e pessoas com deficiência. Brasília: IBGE, 2010. Disponível em: <http://www.ibge.gov.br/home/estatistica/populacao/ censo2010/caracteristicas_religiao_deficiencia/default_ caracteristicas_religiao_deficiencia.shtm $>$. Acesso em: 08 set. 2012.

MORAES, H. S. Projeto conceitual de sistemas de assento para cadeira de rodas: uma abordagem sistemática. 2009. $142 \mathrm{f}$. Dissertação (Mestrado em Design)-Universidade Federal do Rio Grande do Sul, Porto Alegre, 2009.

PELOSI, M. B. A. O papel do Terapeuta Ocupacional na Tecnologia Assistiva. Cadernos de Terapia Ocupacional da UFSCar, São Carlos, v. 13, n. 1, p. 39-45, 2005.

RODRIGUES, D. S. et al. Caracterização das pessoas com deficiência em idade economicamente ativa e mapeamento das instituiçóes de assistência atuantes no município de São Carlos. Cadernos de Terapia Ocupacional da UFSCar, São Carlos, v. 17, n. 2, p. 107-118, 2009.

VERGARA C. S. Projetos e relatórios de pesquisa em administração. São Paulo: Atlas, 2009.

\section{Contribuição dos Autores}

Cláudia Regina Cabral Galvão - Estruturação da coleta e análise dos dados, redação e revisão do texto. Bárbara Iansã de Lima Barroso - Redação e revisão do texto, organização das fontes. Daniela de Castro Grutt - Coleta dos dados, redação e revisão do texto. 